\title{
The ocean, our climate and the earth's health*
}

\author{
J.L. PELEGRÍ, I. ALONSO and J. ARÍSTEGUI \\ Facultad de Ciencias del Mar, Universidad de Las Palmas G. C., Canary Islands, Spain.
}

\begin{abstract}
SUMMARY: The ocean is the major element controlling the long-term stability of the earth's climate. It involves a complex pattern of interrelations between its physical, geological, chemical and biological components: the greater the complexity and diversity of these links the more robust is the stability of the system, and the healthier the earth. A set of papers that resulted from communications presented at a workshop held in Las Palmas on November 1998 emphasises the need for an interdisciplinary approach to the ocean.
\end{abstract}

Key words: earth's health, climate, ocean, interdisciplinary science.

\section{INTRODUCTION}

One possible path to scientific progress consists in encouraging the scientific community to analyse very specific problems, usually within an already quite specific subject, and leaving the assemblage of the puzzle to just a few "geniuses". Such an approach is still stimulated by a rather unchanging structure in many universities and research centres, and even by the funding criteria used by some major agencies. In some aspects this "compartmental" view appears as an advantage: the scientist may simply concentrate on the problem itself and pursue it to the last consequences, sometimes a life long task, with no need to understand how the problem compares with or fits within related issues. But this narrow-minded approach has considerable disadvantages, the major one being a likely loss of perspective, the fact that you get one single picture of a complex problem, which may actually be quite distorted.

\footnotetext{
*Received October 15, 2000. Accepted November 12, 2000.
}

A second possibility is based on the premise that science will advance at a pace that is proportional to the level of common knowledge and participation. This second approach recognizes the hard and continuous analysis of a specific problem as essential in science, but emphasizes that scientific progress will come from the simple requirement that every scientist keeps a wide perspective. In this course each scientist benefits from and contributes to several different disciplines and provides a continuum compendium effort, identifying if one's conclusions fit within the overall picture.

Today's Oceanography is a clear example of the advantages of the above wide perspective. A physical oceanographer, for example, benefits from the results of his colleagues who work in chemical, biological, and even geological problems. Collaborative work in Oceanography has the further benefit of sharing costly infrastructure, like ships, buoys, and remote sensing. Here we wish to emphasize the need for such an interdisciplinary approach to the ocean, not only from a practical point of view but also as a compelling task 
to gain understanding in crucial issues of the earth's climate and life as mankind knows it. This is particularly important since mankind has a very important feedback effect on climate: mankind is the result of the earth's current climate but it now has the potential to modify it. The question is, we believe, whether this modification may be so fast that many species, including human beings, may have no time to adjust to it, leading to unpredictable consequences. Such climate instability, leading to a substantial reduction in biodiversity, would be a clear signal of the earth's poor health.

\section{THE OCEAN AND OUR CLIMATE}

The role of the ocean is extraordinary in today's economic development (fisheries, living and non living resources, transportation, recycling of anthropogenic materials, etc.) but it is even more important in controlling the present and future of the living earth. The ocean means life and a complex pattern of interrelations between its physical, geological, chemical, and biological components. The greater the complexity and diversity of these links, the more robust the stability of the system will be. And it is the stability of this complex network, not just one single characteristic such as the mean earth's temperature, which determines the health of the earth. The task of comprehending the whole picture goes beyond current human capability but the future of mankind forces us to undertake it.

The ocean plays a principal function in controlling two fundamental elements of the global biogeochemical network, i.e. greenhouse gases and energy fluxes, but it also has a direct effect on the earth's population through specific issues such as the mean sea level and its living and non-living resources. The importance of the ocean in the carbon cycle is highlighted by the current difficulty in matching the carbon balance in the biosphere, i.e. given the amount of carbon that has been produced since the industrial revolution it turns out that there is too little carbon in the atmosphere. How and where the carbon excess goes, whether it is because of assimilation by phytoplankton or because of dissolution and transfer to the deep ocean, is unknown, but the fundamental regulating role of the ocean is unequivocal. Changes in ocean biodiversity, for example, would lead to modifications in the structure of plankton communities and, therefore, in the role that marine biota plays in the transfer of atmospheric carbon dioxide into the ocean.
The buffering significance of the ocean probably reaches its maximum expression in the earth's heat balance. It is certain that temperature changes undergone by the earth in the past, especially its latitudinal gradients, have not been directly caused by changes in the sun's radiation level but, paradoxically, radiation is the only ultimate source for these changes. The conclusion is that temperature, as well as many other properties that characterise (but do not constitute) our climate, do have an extraordinary sensitivity to radiation changes. Such sensitivity is indicative of major positive feedback mechanisms within the living ocean, with all its physical, chemical and biological components playing major roles. Specific issues such as the deep thermohaline circulation, and its sensitivity to changes in precipitation, are of extreme importance. The relation between living and non-living phenomena may also be of extraordinary relevance, currently being very underestimated. A good example is the alteration of heat and water exchange between the atmosphere and terrestrial regions (because of increased deforestation), or between the atmosphere and the ocean (because of modified primary production). These changes could lead to substantial modifications in the wind and precipitation regimes, which in turn would influence the ocean circulation patterns and so on.

\section{OUR CLIMATE AND THE EARTH'S HEALTH}

From the above discussion we can possibly foresee that the ocean is the major component determining the earth's health, and that climate is a description of the complex set of links that lead to such health. An illustrative analogy may be the health of a living creature: it is controlled by a complex set of links (climate) between its major vital systems (ocean and biosphere), but will deteriorate if what it eats and breathes is unhealthy (radiation and atmospheric conditions). In the earth, as well as in the above example, the least precise element is the identification of the complex set of links, so it seems worth spending some words on what we mean by the earth's climate.

According to Barnhardt (1957) the word climate comes from the Greek "clima-ata" which means the slope of the earth from the equator to the poles. This is in nice agreement with an appealing global picture, i.e. the slope is a local function which depends on a global distribution. It contrasts, however, with common usage as expressed in major dictionaries (e.g. 
meteorological conditions that prevail in a location for a period of years), which essentially define what we would call the "seasonal or annual mean weather". Oort and Peixoto (1992) have used a much more statistical definition: "set of mean and statistical quantities of superior momenta that characterize the structure and behavior of the atmosphere, hydrosphere, and cryosphere for a time period".

Oort and Peixoto's (1992) definition describes a state but does not go into any consideration of the processes, so it cannot be used for our purposes. Instead we propose the following definition: "a state of near equilibrium in each region of the earth, and over the earth as a whole, that results from local/global fluxes and rates of change of energy, mass, linear momentum, angular momentum, fresh water, nutrients, carbon, minor and trace elements... whose origin is the solar radiation". According to this definition the earth's climate is the main indicator of the stability of the biosphere, i.e. the health of the earth as we know it. The state of equilibrium would be robust at human scales, although delicate at geological scales.

\section{AN INTERDISCIPLINARY VIEW OF THE OCEAN}

Every year since 1995 our School of Marine Sciences (Facultad de Ciencias del Mar, Universidad de Las Palmas de Gran Canaria) has held a one-week workshop on Oceanography named "Taller y Tertulia de Oceanografía". During the first couple of years the workshop addressed mainly Physical Oceanography issues but since 1997, as a result of a closer collaboration between the different oceanographic research groups in the School of Marine Sciences, it moved into a fully interdisciplinary oceanographic perspective. The 1998 edition, held on November 2 to 7, was named "An interdisciplinary view of Oceanography", responding to the conviction that the future of Oceanography in the Canary Islands had to be the outcome of an integrating effort.

The 1998 workshop had 34 oral communications, 15 posters, and several practical sessions (oceanographic instrumentation, designing an oceanographic cruise, geophysical laboratory experiments, and remote sensing), with a total of about 200 participants. The oral communications were given by scientists from several European and American countries, while most posters were prepared by students from the School of Marine Sciences. Although the proceedings of the workshop were published with extended abstracts, most participants agreed to work out their talks and posters as manuscripts, which would then be submitted during the next year. Meanwhile, thanks to the collaboration of Celia Marrasé and Carles Pedrós (Institut de Ciencies del Mar, CSIC), we reached an agreement that the manuscripts could be presented as a special issue of Scientia Marina. All manuscripts followed the rigorous peer review process of papers published in regular journal issues and a total of 28 papers were finally accepted for publication.

The outcome, we believe, is a coherent set of interdisciplinary papers that display the fundamental relation between Biology, Chemistry, Geology and Physics when examining a specific oceanographic problem or a regional ocean, or when working on technical issues such as field instrumentation, remote sensing, and laboratory equipment. They clearly illustrate the necessity of a global approach to the ocean, far away from the separate compartment philosophy, as the only way to understand its crucial interactions.

\section{ACKNOWLEDGEMENTS}

The "Taller y Tertulia de Oceanografía" held at Las Palmas de Gran Canaria in November 1998 was possible thanks to grants from Consejería de Educación, Cultura y Deportes of the Canary Islands local government and the Spanish Ministerio de Educación y Cultura. The publication of this special issue has been possible thanks to financial support from Viceconsejería de Educación, Viceconsejería de Medio Ambiente, and Viceconsejería de Pesca, all from the Canary Islands local government, a grant by the Spanish Ministerio de Ciencia y Tecnología, and the collaboration of the Universidad de Las Palmas de Gran Canaria. The authors, as invited editors of this supplement of Scientia Marina, are indebted to the Chief Editor, Carles Pedrós-Alió, the Technical Editor, Jordi Corbera and the Journal Secretary, Victoria Martínez de Albéniz, for all their help and support throughout the several stages in the preparation of this special issue.

\section{REFERENCES}

Barnhardt, C. L.- 1957. The American College Dictionary. Random House, $1431 \mathrm{pp}$.

Peixoto, J. P., and A. H. Oort.- 1992. Physics of Climate. American Institute of Physics, 520 pp. 
